\title{
Notas sobre a obra A Pátria (1919), de Pedro Bruno
}

Angela Maria Soares Mendes Taddei*

\section{Resumo}

Este artigo tratará de um símbolo nacional inequívoco, a bandeira republicana brasileira, desenhada por Décio Villares e retratada por um pintor acadêmico da primeira metade do século 20 . O ponto de partida de nossa reflexão será a obra $A$ Pátria, composição em óleo sobre tela, pintada em 1919 por Pedro Bruno e exposta na mostra permanente do Museu da República, no Rio de Janeiro. Começaremos por reportar as circunstâncias sócio-históricas que, no início da República, testemunharam as batalhas simbólicas a respeito da adoção de uma bandeira nacional francamente positivista. $O$ quadro $A$ Pátria será abordado na sua dupla condição de signo icônico, vinculado à representação mimética do mundo, e de signo museológico, orientado para a consagração mnemônica. Uma análise formal da obra buscará responder à nossa pergunta maior: em que medida as representações da nação, construídas por alguns intérpretes do Brasil, são explicitadas ou esquecidas pelo discurso iconográfico em questão? Ou, dito de outro modo: haverá correspondências ou discordâncias entre os tradicionais narradores da palavra e este narrador da imagem em particular?

Palavras-chave: Símbolos nacionais, Brasil. Iconografia. Memória social.

\section{Notes on the painting A Pátria (1919), by Pedro Bruno}

\begin{abstract}
This article will focus on an unequivocal national symbol, namely the republican Brazilian flag, which was designed by Décio Villares and reproduced by an academic painter along the first half of the twentieth century. The departing point of our reflection is a work entitled $A$ Pátria, an oil on canvas, painted in 1919 by Pedro Bruno and exposed at the permanent exhibition of Museu da República, in Rio de Janeiro. We will begin by reporting the socio-historical circumstances at the first Brazilian republican times that have witnessed the symbolic battles over the adoption
\end{abstract}


of a markedly positivist national flag. The painting $A$ Pátria will be approached in its double aspect of both an iconic sign, related to the mimetic representation of the world, and also a museological one, headed to mnemonic consecration. A formal analysis of the painting will essay to respond our major point which writes: to what extent representations of the nation, built by a few Brazil interpreters, are explicited or forgotten in this very iconographic discourse? Or, in other words, are there agreements or disagreements between traditional word narrators and this particular image narrator?

Key-words: National emblems, Brazil. Iconography. Social memory.

\section{Uma palavra primeira}

Salve, lindo pendão da esperança, Salve, símbolo augusto da paz!

Tua nobre presença à lembrança A grandeza da pátria nos traz.

(Hino à Bandeira, letra de Olavo Bilac e música de Francisco Braga)

Auriverde pendão de minha terra Que a brisa do Brasil beija e balança,

Estandarte que a luz do sol encerra E as promessas divinas de esperança.

(Navio Negreiro, Antônio de Castro Alves)

Pavilhão, flâmula, estandarte, lábaro, pendão: esses vocábulos, por solenes e eruditos, nos remetem aos hinos cívicos, que um dia aprendemos a cantar, e aos poetas nacionalistas, que desde sempre vêm cantando a pátria, suas glórias e seus símbolos. E é justamente sobre um símbolo nacional inequívoco, a bandeira republicana, mediada pela paleta de um pintor acadêmico da primeira metade do século 20, que versarão as Notas que ora se iniciam. 
Nosso ponto de partida será a obra intitulada $A$ Pátria (Figura 1), composição em óleo sobre tela, de 1,90 m por 2,78 m, pintada em 1919 por Pedro Bruno, e exposta na mostra permanente do Museu da República, sediado no Palácio do Catete, no Rio de Janeiro (1).

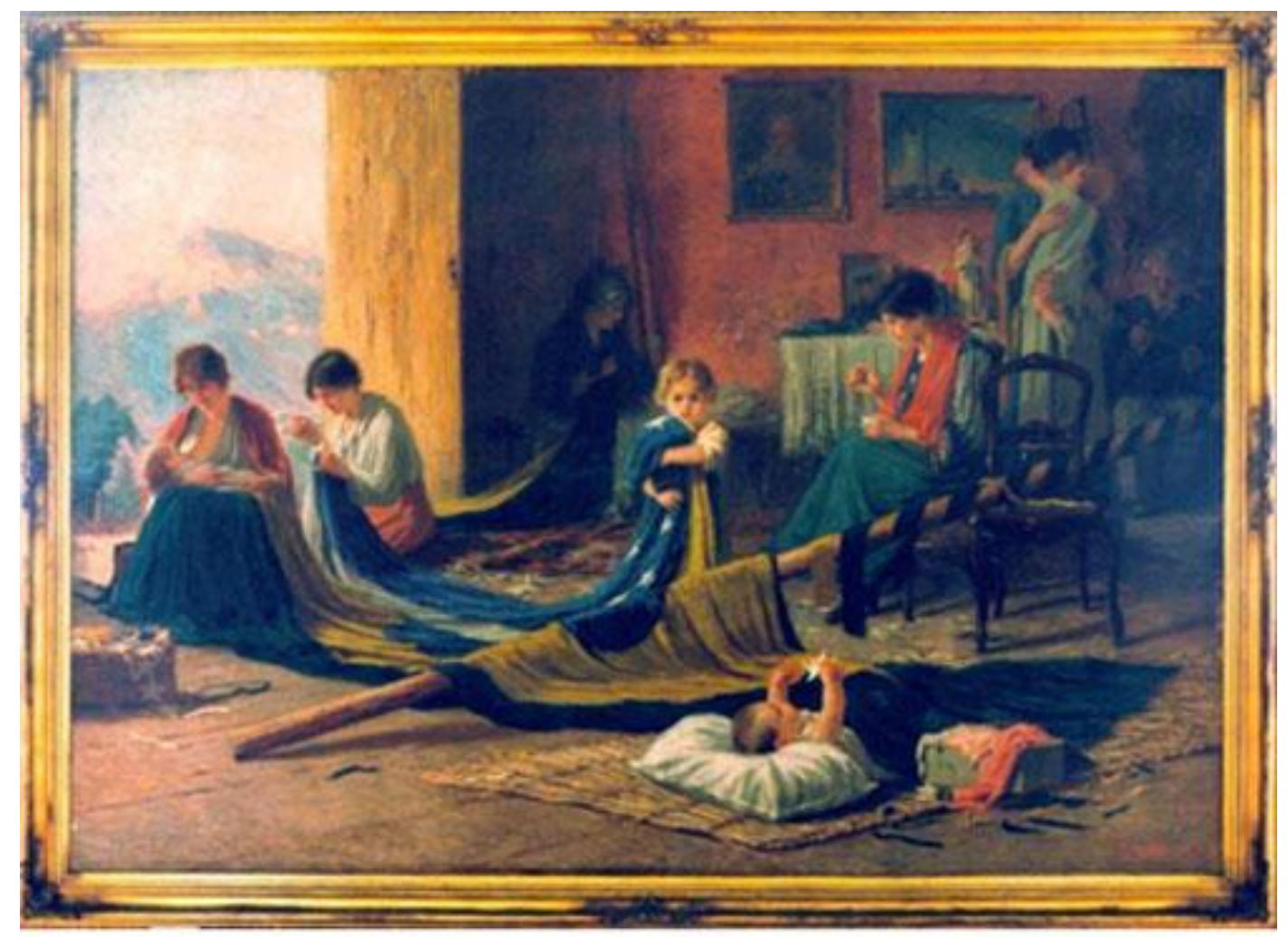

Figura 01 - Quadro A Pátria, de Pedro Bruno (1919), óleo sobre tela. Página eletrônica do Museu da República, Rio de Janeiro, www.museudarepublica.org.br .

Num primeiro momento, reportaremos uma notícia biográfica do pintor Pedro Bruno e delinearemos as circunstâncias sócio-históricas - ideias e modos de ver e ser de um Brasil republicano - que eclodiam com maior intensidade no Rio de Janeiro, então capital federal, e reverberavam na produção artística do período.

Seguiremos tratando da especificidade do objeto em análise na sua dupla condição de signo icônico, vinculado à representação mimética do mundo, e de objeto museológico, voltado para a consagração mnemônica. 
Procederemos então a uma análise formal da obra, que não pretende ser exaustiva, mas que buscará iluminar nossa pergunta maior: em que medida as representações da nação, construídas por alguns tradicionais intérpretes do Brasil, são explicitadas ou negligenciadas pelo discurso iconográfico em questão? Ou, dito de outro modo: haverá correspondências ou discrepâncias entre os narradores da palavra e este narrador da imagem em particular?

Por fim, mas sem a ambição de uma conclusão fechada, sintetizaremos os efeitos de sentido decorrentes da análise da obra de Pedro Bruno.

\section{Das circunstâncias}

Pedro Paulo Bruno nasceu em Paquetá em quatorze de outubro de 1888 e morreu no mesmo local em dois de fevereiro de 1949. Cedo se interessou pelas artes plásticas e tornou-se, além de pintor, escultor e paisagista. Cursou a Escola Nacional de Belas Artes (ENBA), no Rio de Janeiro. Em 1919, foi agraciado com o Prêmio de Viagem ao Estrangeiro por conta da obra $A$ Pátria, objeto de nossa investigação, que figurou no verso da antiga nota de duzentos mil cruzeiros (www.dezenovevinte.net/bios/bio pb.htm).

Modificadas a moeda, a idílica ilha de Paquetá, a cidade do Rio de Janeiro e muitos dos instrumentos jurídico-políticos daquele ontem, nem por isso a tela de Pedro Bruno perdeu seu cunho de documento. José Murilo de Carvalho, em seu livro $A$ formação das almas (1990), aponta A Pátria como uma tentativa de conciliação entre correntes republicanas opostas em disputa pela fixação dos símbolos nacionais. Espreitemos esses primeiros tempos da República e ouçamos as vozes que se alternam e se altercam na arena do novo regime político.

A mudança da Monarquia para a República, como nos afiança Carvalho em texto já tornado clássico (1987), não teve a marca do protagonismo popular. Ao invés, o novo regime foi urdido no espaço fechado de gabinetes elegantes, redações de jornais e escolas militares. Às vésperas do quinze de novembro, nos relata Emília Viotti da Costa (1999), um clima de boataria e conspiração uniu na Corte uma parte do Exército, fazendeiros paulistas e membros das classes médias urbanas. Se o gesto decisivo coube a Deodoro da Fonseca, um alto escalão do Exército, 
conservador e prestigiado, outros segmentos das elites brasileiras de então teceram a trama do projeto republicano, matizado por visões de mundo diferenciadas.

Sob o conceito de utopias republicanas, Carvalho (1990) identifica um liberalismo de inspiração americana, um jacobinismo de extração francesa e um positivismo comteano. Embora a facção liberal tenha se tornado hegemônica já no início do século 20, nos primórdios, seguidores de cada uma dessas utopias encetavam embates acirrados pela imposição de um imaginário simbólico que, para além da palavra falada e/ou escrita, atingisse o grosso da população brasileira, ainda pouco afeita às letras.

No ano zero da República, era preciso que se instituíssem novos símbolos nacionais. Depois da circulação de um malsucedido exemplar de bandeira brasileira à imagem e semelhança da bandeira norte-americana, logo repudiado, os positivistas foram mais eficientes não só em conceber um outro modelo desenhado com presteza por Décio Villares -, mas ainda em defendê-lo das muitas críticas de que foi alvo. A nova bandeira conservava de sua antecessora imperial o campo verde, o losango amarelo e as estrelas. Substituía os elementos figurativos e marcadamente monárquicos - os ramos de tabaco e café, o escudo heráldico, a coroa, a cruz e a esfera armilar de ressonância portuguesa - por uma esfera azul, onde figuravam, além de estrelas representando os estados e a constelação do Cruzeiro do Sul, uma faixa branca com a legenda positivista Ordem e Progresso (2).

Os protestos mais acerbos tiveram por objeto justamente o lema positivista. Teixeira Mendes, positivista ortodoxo, justificou, no Diário Oficial de 24 de novembro, a utilização da divisa, invocando a filosofia comteana, a união entre passado e futuro que se evidenciava no novo símbolo, a necessidade de se conciliar o desenvolvimento da ciência e o desenvolvimento da nação com vistas à confraternização universal, último estágio da evolução positiva.

O Diário do Commercio, por seu turno, questionou a inclusão de uma palavra de ordem vinculada a uma seita religiosa particular em um símbolo que deveria representar a pátria e todos os integrantes da nação, fossem quais fossem seus credos. 
Outras reações desfavoráveis se fizeram ouvir com relação à disposição das estrelas, que, em princípio, reproduziria o céu do Rio de Janeiro na manhã de quinze de novembro de 1889. Astrônomos estrangeiros apontaram um equívoco científico na configuração do céu da bandeira e Eduardo Prado - escritor, jornalista e monarquista ferrenho - chegou mesmo a escrever uma obra intitulada Bandeira Nacional em que explicitava esta incorreção (www.machadodeassis.org.br/abl).

A polêmica sobre a bandeira, prossegue Carvalho, gerou, já no mandato de Floriano Peixoto, um projeto de reformulação: pretendia-se abolir a divisa positivista, suprimir as estrelas e acrescentar sobre a esfera azul as armas da república. Diante desta tentativa de mudança, as reações foram extremadas: em todo país, civis e militares manifestaram-se a favor da manutenção da bandeira positivista e acabaram por frustrar este projeto de mudança.

É esta bandeira republicana, já reconhecida como representação da pátria e reverenciada em monumentos, mitos e ritos cívicos, que será o tema da tela de Pedro Bruno, pintada trinta anos mais tarde. Trata-se de obra de gênero histórico, segundo a taxionomia adotada pela Academia Imperial de Belas Artes ao longo do século 19. (ZíLIO, 1997). De cunho figurativo, a pintura narra a confecção de uma bandeira no interior de um ambiente doméstico - uma espécie de sala de costura. Segundo o Museu da República (www.republicaonline.org.br), instituição que abriga a obra, esse "flagrante" imaginado pela expressão artística de Bruno corresponderia ao episódio da elaboração da primeira bandeira republicana, costurada e bordada pela mulher e as filhas de Benjamin Constant, ideólogo maior do positivismo entre nós, e oferecida à Escola Militar em 1890.

\section{Da especificidade do objeto}

Abordar uma obra de arte como objeto de análise requer alguns cuidados. Talvez o primeiro deles seja reconhecer sua polissemia.

Em termos semióticos, por mais diferenciados que sejam seus significantes suportes materiais que remetem aos sentidos - toda obra enquanto signo (PEIRCE, 1972) deflagra múltiplos significados - conceitos ideacionais validados pela 
sociedade. Isto quer dizer que, diante de uma obra de arte, são muitas as leituras/interpretações possíveis: históricas, políticas, sociológicas ou psicanalíticas; estéticas ou meramente afetivas. A rigor, todos esses olhares têm validade e dependem muito mais do observador - de suas lentes, repertórios e objetivos - do que propriamente da coisa observada (3).

O quadro $A$ Pátria constitui-se assim em um signo (4). Mais exatamente, em um signo icônico se atentarmos para a sua característica de obra figurativa. Tendo como telos a representação mimética do mundo, o ícone, segundo Peirce, estabelece entre seu significante e seu referente uma relação de analogia. Em termos pictóricos, essa verossimilhança pretendida entre o mundo da tela e o mundo da realidade se constrói pela adoção de dispositivos técnicos como, por exemplo, a proporção áurea e a perspectiva monocular (HAUSER, 1995).

Além de signo icônico, a obra de Pedro Bruno, evocadora dos primórdios da república, aproxima-se do conceito de lugares de memória, cunhado por Pierre Nora (1993). Os lugares, assim referidos, não se conectam necessariamente a aspectos geográficos: se museus, bibliotecas e arquivos se definem inequivocamente como casas de memória, guardiãs de patrimônios locais, regionais e nacionais, objetos em diferentes suportes - dos textos literários à produção artística iconográfica, de que é exemplo o quadro de Bruno, - podem instaurar, perpetuar e deflagrar memórias vinculadas a certo grupo social em certo espaço-tempo.

\subsection{O objeto per se: análise e interpretações}

Signo icônico e objeto museológico, a obra em questão, de dimensões monumentais, apresenta-se como um objeto bidimensional, que, recorrendo à perspectiva, busca a ilusão da tridimensionalidade. No ponto central da composição, uma criança de aproximadamente quatro anos, envolve com os dois braços uma ponta da bandeira republicana - como se fora um bichinho de pelúcia - e volta seu olhar firme para nós outros, espectadores. Outras crianças, de diferentes idades, também participam da cena: no fundo, à direita, uma criança é confortada pela mãe, que está de pé; em primeiro plano, um bebê, deitado sobre uma almofada e coberto por parte da bandeira, brinca com uma das estrelas a serem aplicadas no símbolo nacional; à esquerda, um bebê pequeno é amamentado pela mãe, que tem os 
joelhos cobertos por outra ponta da bandeira. A geração mais velha está representada por um personagem feminino e um masculino que se encontram sentados no fundo do cômodo, em zona de quase obscuridade. Como elementos cenográficos deste interior burguês, representações de segundo grau: um quadro retratando Deodoro, um quadro com a imagem de Tiradentes e uma estátua de Nossa Senhora. Quatro mulheres, simetricamente dispostas, concentram-se com igual empenho nas tarefas de bordar a bandeira e/ou cuidar das crianças. À esquerda, a porta escancarada deixa entrar a luz do dia e entrever uma paisagem montanhosa. Finalmente a bandeira, pousada no centro desse ateliê improvisado, circundada por caixas de costura, meadas de linha e estrelas que se espalham em desalinho, tem uma das extremidades de seu mastro no chão e outra apoiada em uma cadeira de estilo francês. $O$ título do quadro, $A$ Pátria, nos fornece pistas para interpretá-lo. Senão, vejamos

Que pátria é essa que se apresenta na obra de Bruno?

Em primeiro lugar, não é a retomada do mito de um paraíso nos trópicos como na descrição de Rocha Pita (5) ou na exaltação romântica de um Alencar. Na composição do espaço pictórico, a natureza aparece de esguelha, na luminosidade oblíqua do sol que adentra o ateliê de costura e nas montanhas que, ao longe, prenunciam a vastidão do território. A flora e a fauna brasileiras, registradas com nitidez nos trabalhos de Frans Post ou Nicolas Taunay, por exemplo, são aqui apenas sugeridas.

Ausentes, por outro lado, estão os habitantes desta capital federal que, antes e depois da modernização à francesa, eram constituídos, em sua maioria, de pardos, negros, ex-escravos e seus descendentes (SEVCENKO, 1998). A mestiçagem, peculiaridade identitária louvada por Gilberto Freyre (1977), aqui não tem registro. E se não mencionamos os índios, foi porque no tempo a que aludimos já tinham deixado de ser uma presença significativa na cidade ainda que tivessem se tornado desde o Império personagens literários e pictóricos na esteira do mito rousseauniano do bon sauvage. Em contrapartida, meninos e meninas, mulheres em idade fértil e representantes da geração mais velha que se reúnem em torno da bandeira são todos brancos, de traços e indumentária europeus. 
À primeira vista, a tela não prioriza a figura do todo-poderoso pater familias, como enunciada por Gilberto Freyre (op. cit). Teriam os novos tempos da República decretado sua extinção? Ainda no âmbito do gênero, a preponderância de personagens femininos nos autorizaria a dizer que Pedro Bruno retratou uma pátriamãe, em releitura da metáfora recorrente em nossos hinos. Contudo, essas mulheres laboriosas em missão cívica - e, naturalmente, não remunerada - estão limitadas ao espaço privado. Filhas da elite, cumprem os papéis sociais desde sempre reservados às mulheres: esposas, donas de casa, mães. Mas, arriscaríamos perguntar: onde se esconderam as muitas amas de leite negras e mulatas que se "alugavam" nos jornais da capital? Onde a mãe preta celebrada por Freyre? Além disso, essas bordadeiras dedicadas em nada se assemelham às alegorias da República, da Liberdade ou da Nação, pintadas como mulheres líderes e agentes da História, que povoaram o imaginário social francês a partir da queda da monarquia. E embora artistas brasileiros positivistas, como Eduardo de Sá e o próprio Décio Villares, tenham produzido algumas figurações da República, calcadas em modelos franceses, essas iconografias femininas entre nós, pondera Carvalho (1990), sempre tiveram que travar um combate surdo e desigual com a onipresença do culto à Virgem Maria. Com efeito, considerando-se o papel relevante da Igreja Católica em nossa colonização, desenvolveu-se no Brasil, como reporta Cristina Costa (2002), a devoção que enfatiza na figura mítica e modelar da Virgem atributos como a pureza, a doçura, a submissão aos desígnios divinos, a vocação para amparar e proteger os filhos.

Como elemento central da obra, a bandeira republicana, metonímia da pátria, distancia-se do tratamento iconográfico tradicionalmente conferido ao símbolo maior da nação. Imagem e representação do Brasil, a bandeira não tem aqui função épica, heroica, grandiloquente: não tremula à frente de um batalhão; não se ergue no topo de monumentos ou na popa de navios; e nem recobre o esquife de mártires em rituais fúnebres. Está antes circunscrita à domesticidade do cotidiano, manuseada por mulheres e crianças, obra em preparação, tornada abrigo, cobertor, quase brinquedo. Sem pompa nem circunstância, o pavilhão auriverde, esvaziado de seu poder hierático, parece estar destinado a congregar brasileiros de todas as idades em torno de um ideal de paz. 
É esta noção de acomodação e síntese de tendências antagônicas que Carvalho (1990) sublinha: o retrato de Deodoro, político conservador, e a estátua da Virgem Maria em princípio destoariam em um cenário positivista de culto cívico. No entanto, toda a arquitetura da obra se constrói sob a égide da idealização. Passados trinta anos do evento que o quadro pretendeu narrar, Pedro Bruno se permitiu algumas licenças poéticas e/ou históricas. Além da incoerência ideológica nos objetos/índices que ocupam o cenário, como aponta Carvalho, os filhos da pátria são todos brancos, bem vestidos e bem alimentados. Passaram incólumes pelas endemias da capital federal. Não germinaram na umidade insalubre dos cortiços postos abaixo pela reforma de Pereira Passos. Quanto às filhas/mães da pátria, são igualmente brancas e bem-nascidas. Serenas, submissas e diligentes, reencenam comportamentos de abnegação cristã. Talvez por isso, referências ao senhor patriarcal apareçam apenas como pano de fundo nos retratos dos heróis e na figura do ancião, parcialmente encobertos por sombras. As mulheres de Pedro Bruno já internalizaram os códigos de sociabilidade próprios a seu gênero. Estão perfeitamente enquadradas nos padrões de uma identidade biologicamente definida, socialmente acessória e politicamente irrelevante. E, o que é mais surpreendente em se tratando de mulheres das elites brasileiras, essas donas de casa exemplares dispensaram amas de leite, mucamas, criadas e serviçais e assumiram integralmente as tarefas que, há milênios, vêm sendo realizadas por mãos femininas no universo do espaço privado.

\section{Em busca de uma síntese}

Obra de arte do gênero pintura histórica e objeto museológico, a abordagem de $A$ Pátria nos fez evocar múltiplas representações do Brasil em tempos diferenciados. Fizemos referência ao Hino à Bandeira, do Bilac parnasiano. Ouvimos o clamor de Castro Alves, poeta abolicionista. Relembramos o entusiasmo de nossos primeiros narradores - escritores ou artistas plásticos - diante dessa terra ao sul do Equador.

Nesta pátria idealizada, pouco representativa da diversidade étnica, cultural ou social dos cidadãos que nela habitaram ou habitam em qualquer momento da sua História, figura, por contraste, uma bandeira nacional a que dificilmente chamaríamos de pendão, estandarte ou lábaro. Este símbolo auriverde espraiado 
pelo chão, íntimo de mulheres e crianças, doméstico e acessível, tal como o concebeu Pedro Bruno, é revisitado, décadas mais tarde, pelo canto de um poeta nosso contemporâneo:

Vontade de beijar os olhos de minha pátria

De niná-la, de passar-lhe a mão pelos cabelos... Vontade de mudar as cores do vestido (auriverde!) tão feias De minha pátria, de minha pátria sem sapatos E sem meias, pátria minha Tão pobrinha! (MORAES, Vinícius de, Pátria minha, 2000, p. 30)

\section{Notas}

(1) Agradeço aqui à museóloga Magaly Cabral, atual Diretora do Museu da República, por autorizar a reprodução fotográfica neste artigo da tela de Pedro Bruno A Pátria, pertencente ao acervo do supracitado Museu, e assim possibilitar que essa minha pesquisa seja divulgada com a representação fotográfica da obra que Ihe deu origem.

(2) "O amor por princípio, a ordem por base, o progresso por fim" era o enunciado original de Auguste Comte. Descartado o amor, reduziu-se 0 enunciado ao dístico que figura em nossa bandeira (www.cienciareligiao.org.br).

(3) O fato de a obra permitir várias leituras não nos autoriza a chegar ao relativismo extremo de imaginar que qualquer interpretação é possível. Exemplificando: o acesso sensorial à obra Guernica, de Picasso, nos informa que estamos diante de um libelo contra a destruição, o aniquilamento. Mesmo que não saibamos que se trata de um ataque nazista a uma pequena cidade na vigência da guerra civil espanhola (leitura histórica). Mesmo que desconheçamos a influência da arte africana na representação da figura humana proposta por Picasso (leitura estética).

(4) Para Peirce, "um signo é [...] algo que representa alguma coisa para alguém, sob algum prisma" (PEIRCE, 1972, p. 26)

(5) "Em nenhuma outra região se mostra o céu mais sereno, nem madruga mais bela aurora; o sol em nenhum outro hemisfério tem raios tão dourados, nem os reflexos noturnos tão brilhantes" [...]

Hiperbólico é o canto das maravilhas de nosso território citado por Chaui, ainda nos primórdios da nossa colonização (ROCHA PITA apud CHAUÍ, 2000, p. 5-6). 


\section{Referências bibliográficas}

BILAC, Olavo; BRAGA, Francisco. Hino à Bandeira. Disponível na página eletrônica da Academia Brasileira de Letras www.academia.org.br/abl. Acesso em: 3 jul. 2008.

CARVALHO, José Murilo de. Os bestializados. O Rio de Janeiro e a República que não foi. São Paulo: Companhia das Letras, 1987.

CARVALHO, José Murilo de. A formação das almas: o imaginário da República no Brasil. São Paulo: Companhia das Letras, 1990.

CASTRO ALVES, Antônio de. Navio negreiro. In: BOSI, Alfredo. História concisa da literatura brasileira. São Paulo: Cultrix, 1994.

CHAUÍ, Marilena. Brasil: mito fundador e sociedade autoritária. São Paulo: Perseu Abramo, 2000.

COSTA, Cristina. A imagem da mulher: um estudo de arte brasileira. Rio de Janeiro: Senac-Rio, 2002.

COSTA, Emília Viotti da. Da Monarquia à República: momentos decisivos. São Paulo: Unesp, 1999.

FREYRE, Gilberto. Casa-Grande \& Senzala: introdução à história da sociedade patriarcal no Brasil. Rio de Janeiro: José Olympio, 1977.

HAUSER, Arnold. História social da arte e da literatura. São Paulo: Martins Fontes, 1995.

MORAES, Vinícius de. Soneto da fidelidade e outros poemas. São Paulo: Ediouro, 2000.

NORA, Pierre. Entre a memória e a história: a problemática dos lugares. (Projeto História). Revista do Programa de Estudos Pós-Graduados em História e do Departamento de História, São Paulo, PUC-SP, n. 10, p. 7-28, dez. 1993.

PEIRCE, Charles Sanders. Semiótica e Filosofia. São Paulo: Cultrix, 1972.

PESQUISA sobre Auguste Comte. Disponível em: www.cienciareligiao.org.br. Acesso em: 4 jul. 2008.

PESQUISA sobre a biografia de Pedro Bruno. Disponível em: www.dezenovevinte.net/bios/bio pb.htm. Acesso em: 3 jul. 2008.

PESQUISA sobre a obra de Pedro Bruno. Disponível na página eletrônica do Museu da República www.republicaonline.org.br. Acesso em: 4 jul. 2008.

PESQUISA sobre a biografia de Eduardo Prado. Disponível na página eletrônica da Academia Brasileira de Letras www.machadodeassis.org.br/abl. Acesso em: 16 abr. 2010.

SEVCENKO, Nicolau. Introdução. O prelúdio republicano, astúcias da ordem e ilusões do progresso. In: SEVCENKO, Nicolau (Org.) História da vida privada no Brasil 3. São Paulo: Companhia das Letras, 1998. 
ZíLIO, Carlos. A querela do Brasil: a questão da identidade da arte brasileira. Rio de Janeiro: Relume-Dumará, 1997.

\section{Crédito}

* Bacharel em Museologia pela Universidade Federal do Rio de Janeiro (UNIRIO), licenciada em Letras pela Universidade do Estado do Rio de Janeiro (UERJ), mestre em Memória Social pela UNIRIO, especialista em Comunicação e Imagem pela Pontifícia Universidade Católica do Rio de janeiro (PUC-Rio) e doutoranda em Ciências Sociais pela UERJ (PPCIS/ FAPERJ).

e-mail: angelatad@gmail.com 